\title{
Ammonia Intoxication at the Work Place - A Case Report
}

\author{
Lorena Maries $^{1}$ and Marina Maries ${ }^{2}$
}

\author{
'Occupational Medicine Department, Sanador Medical Center, Bucharest, Romania; lorenamaries@yahoo.com \\ ${ }^{2}$ Occupational Diseases Compartment, Sibiu Clinical County Hospital, Romania
}

\begin{abstract}
Objectives: We report a case of intoxication with irritant vapors (ammonia). Methods: The patient was admitted to the Occupational Diseases Compartment of the Sibiu Clinical County Hospital, Romania, monthly- in January, February, March, April in 2015, for respiratory symptomatology, which was initially included in the manifestations of the intoxication with irritant vapors, later for the chronic post-intoxication residual respiratory effects. Results: The patient, though young (36 years old), is now retired on medical ground, because of the pulmonary complications which occurred despite the intensive treatment. Discussion: The intoxication occurred because of a work accident at a preserved meat product factory in the city. We emphasize the importance of preventing such situations.
\end{abstract}

Keywords: Ammonia, Gas, Intoxication, Irritant Vapours, Work Accident

\section{Introduction}

Ammonia is a colorless gas, stable at room temperature, lighter than air, with a pungent smell. At $-33^{\circ} \mathrm{C}$ or at a pressure of at least 10 bars, it liquefies to a colorless fluid. It is highly soluble in water, forming ammonium hydroxide $\left(\mathrm{NH}_{4} \mathrm{OH}\right)$. It is a strong alkaline that displays high corrosive properties. Because of its chemical properties, it is toxic to human in all forms of exposure. It causes alkaline chemical burns to the skin, to the eyes and particularly to the respiratory system, proportional to the duration and type of exposure, to the strength and $\mathrm{pH}$ of the gas or fluid ${ }^{1}$.

Ammonia is used mainly as fertilizer in agriculture and as refrigerant in industrial cooling equipment. It is also used in the production of nitrous fertilizers, of nitric acid, the synthesis of urea, the manufacture of dyes and paints, in refineries ${ }^{2}$.

Generally, the clinical manifestations of acute exposure are immediate ${ }^{1}$. The respiratory tract is the most exposed one, because of the inhalation of ammonia ${ }^{2}$. Acute exposure to high ammonia concentrations may lead to tracheobronchitis with the severe obstruction of the air flow, followed by its chronic obstruction with bronchiectasis ${ }^{3}$. Exposure to a considerable concentration of ammonia gas may be fatal in a matter of minutes; asphyxiation may appear after exposure in confined and poorly ventilated spaces ${ }^{1}$.

\section{Case Presentation}

The patient H.I.C., 36 years old,a refrigeration technician, was the employee of a preserved meat product factory in the city, being in charge with the maintenance of the fac- tory's cooling equipment. According to the patient's own statement, in December 2014, he went, accompanied by a rescuer, to check the company's ammonia gas installation, which suffered a failure. During the checks, he dropped a hose, which led to the release of very highly concentrated ammonia gas. Thus, although he did wear a mask and despite the fact that the exposure only took several minutes, the patient blacked out, being removed by the rescuer and transported to the Emergency Admission Unit. He was then transferred in the care of the internist who consulted him, in the Medicala I section of the Sibiu County Hospital, because the Occupational Health physician was on annual leave. At this initial admission in hospital, the major symptoms were treated (oropharyngeal ulcerations, dysphonia, mixed ventilatory dysfunction with obstruction on the large airways and severe on the small airways, conjunctival hyperemia), the event was marked and declared occupational disease and work accident.

The patient returned on the $5^{\text {th }}$ of January, this time directly in the Occupational Diseases Compartment, complaining about marked dysphonia, mixed dyspnea, sweats, and asthenic-vegetative syndrome. From a clinical viewpoint, at the admission, we noted as pathological-sibilant rhonchi on both pulmonary surfaces, accentuated dysphonia.

The chest X-ray did not show any evolving lesions, condensation processes. An ENT consultation, noted mobile vocal folds, however with an accentuated bilateral congestion; the recommendation was to administer hydrocortisone hemisuccinate i.v., Ampicillin, Fluconazole, Vitamins A and E, Omeran. The spirogram showed mixed ventilatory defects, mainly severe 
obstructive. All the blood tests that were performed (complete blood count, urinalysis, biochemistry) showed normal results; also, the pharyngeal exudate did not detect bacteria or fungi. In this phase, the case was interpreted as - status after occupational intoxication with irritant vapors (ammonia); irritation syndrome of the upper respiratory tract - acute secondary laryngitis; acute secondary tracheal bronchitis; mixed ventilatory dysfunction, mainly severe obstructive. The patient followed antibiotic therapy in association (Ampicillin, Gentamicin), massive corticoidparenteraltherapy, and also treatment with antimycotics, proton pump inhibitors, vitamins, NSAIDs. The patient was discharged in an improved state of health with recommendation of reassessment in 90 days.

The patient returned to the Occupational Diseases Compartment on 19.01.2015, accusing marked dyspnea, dysphonia, asthenia, fatigability, sweat. Clinically, at the admission, we noted sibilant rhonchi mostly on the right side, dysphonia, productive cough, sweaty teguments. The chest X-ray showed an accentuated bilateral peribronchovascularinterstitium, increased hila, general hyper-transparency.

We recommended an Ophthalmology consultation, which showed spastic angiopathy, and a Cardiology consultationwhich showed stage II high blood pressure, for which the recommendation was Nebilet $5 \mathrm{mg}$ per day. It is known that the systemic effects after acute exposure to high concentrations of ammonia include high blood pressure, bradycardia, cardiorespiratory arrest, cyanosis ${ }^{1}$. He also underwent a Pulmonology consultation, following which he was diagnosed with "chronic bronchitis with accentuated functional deficit", he received indication of lung $\mathrm{CT}$ and treatment with Aeriusand Clenil jet. At the stress test-going up and down 2 floors 2 times - he did not present any pulmonary auscultation or BP changes. The blood count showed lymphocytopenia with monocytosis and high ESR, and the biochemistry showed high fibrinogen values. In this phase, the case was interpreted as "Status after occupational intoxication with irritant vapors (ammonia); acute secondary laryngitis; spastic secondary bronchitis, right basal interstitial lung disease, stage I/II HBP under treatment". The patient received therapy with antibiotics (Amoxicillin, Cefuroxime), massive corticoid therapy parenteral, bronchodilators, proton pump inhibitors, vitamin therapy. He was discharged with recommendation of admission in Pulmonology for the lung CT and specialized evaluation. We consider that this symptomatology corresponded to the second stage of the intoxication with irritant vapors.

The patient returned to the Occupational Diseases Compartment on 26.02.2015, complaining about marked dyspnea at small effort, productive cough with aeration. Clinically, at the admission-lungs-sibilant rhonchi, oscillating blood pressure values. The chest X-ray showed a pulmonary interstitium within normal ranges. The patient was admitted in the meantime at the Pulmonology ward where the CT scan was performed, which did not show any modifications. The blood count indicated neutrophilia with lymphocytosis and monocytosis. In this phase, the case was interpreted as "Status after occupational intoxication with irritant vapors (ammonia); acute respiratory failure; acute secondary obstructive lung diseasewith spastic component, HBP stage II under treatment". The patient continued the therapy with antibiotics (Gentamicin, Cifran), parenteral corticoids, proton pump inhibitors, bronchodilators. The patient was discharged from hospital on 20.03.2015 in an improved state of health, with a sick leave of 31 days.

The patient returned again to the Occupational Diseases Compartment, in April, complaining about the same symptomatology. Clinically, at the admission - sibilant rhonchi, wheezing, high blood pressure $(\mathrm{BP}=150 / 90 \mathrm{mmHg})$, without any other modifications in the clinical examination. The blood tests continued to indicate a high fibrinogen value, otherwise the blood count was normal. In this phase, the case was interpreted as "status after occupational intoxication with irritant vapors (ammonia); chronic secondary respiratory failure, secondary asthmatic bronchitis, HBP stage II under treatment". The patient followed therapy with antibiotics(Doxycycline), bronchodilators, antihypertensives.

\section{Discussions}

This is a rather severe form of intoxication with irritant vapors, which went through all the 3 stages of the diseases (irritation syndrome of the upper airways, occlusive bronchiolitis, acute toxic pulmonary edema), despite the insistent treatment. The disorder occurred after an exposure of several minutes (we could not determine the time precisely from the patient's description), but at a very high concentration of ammonia.

Massive inhalation of ammonia gas may be fatal or it may lead to severe pulmonary impairment, which could require assisted respiratory support (mechanical ventilation) $)^{4,5}$, or even indicate the necessity of a lung transplant ${ }^{2}$.

In the case that we have described, the impairment was not so severe to require such measures. Nevertheless, complications did occur, despite the fact that the victim had been removed quickly from the contaminated environment, admitted to the hospital and treated intensively with corticosteroids in oral and parenteral administration. In fact, it is known the lesions caused by ammonia gas inhalation are followed by the installation of a chronic pulmonary disease ${ }^{1,6}$.

The case was signaled and declared acute intoxication, occupational disease and work accident. The employer asked the patient to come back to work from the last sick leave, the competent authorities announced that the employee resumed his activity and the case was closed. Later, because the employee could not fulfill his tasks, he had to resign and then to retire. At present, the patient is retired on medical ground; because of 
the fact that he had returned to work, he cannot benefit from a pension of disability. We do note that this is a young person (36 years old), who is left with complications that require longterm treatment and special conditions should he ever wish to work again; apart from its medical characteristics, the case also has a legislative and social peculiarity.

We emphasize the importance of preventing such situations. The workers should be familiar with the work environment, and comply with occupational safety measures; we also stress the importance of the presence of well-trained and equipped rescue teams, able to act quickly if an accident were to occur.

\section{References}

1. Makarovsky I, Markel G, Dushnitsky T, Eisenkraft A. AmmoniaWhen Something smells wrong- toxic chemical compounds. IMAJ. 2008 Jul; 10.
2. Lalic H, Djindjic-Pavicic M, Kukuljan M. Ammonia intoxication on workplace- Case report and a review of literature- Coll. Antropol. 2009; 33(3):945-9. PMid:19860130

3. Sundblad B-M, Larsson B-M, Acevedo F, Ernstgard L, Johanson $\mathrm{G}$, Larsson $\mathrm{K}$, et al. Acute respiratory effects of exposure to ammonia on healthy subjects. Scand J Work Environ Health. 2004; 30(4):313-21. https://doi.org/10.5271/sjweh.800

4. O'Kane GJ.Inhalation of ammoniavapour. Areport on themanagement of eight patients during the acute stages. Anaesthesia. 1983; 38:1208-13. https://doi.org/10.1111/j.1365-2044.1983.tb12527.x PMid:6660462

5. Bhalla A, Mahi S, Sharma N, Singh S. Glycopyrrolate in toxic exposure to ammonia gas. J Emerg Trauma Shock. 2011; 4:140-1. https://doi.org/10.4103/0974-2700.76830 PMid:21633586 PMCid:PMC3097567

6. Leduc D, Gris P, Lheureux P, Gevenois PA, De Vuyst P, Yernault JC. Acute and long term respiratory damage following inhalation of ammonia. Thorax. 1992; 47:755-7. https://doi. org/10.1136/thx.47.9.755 PMid:1440475 PMCid:PMC474816 